$\mathrm{PH} \mathbf{8 9}$

\title{
Museo Arqueológico de Espera (MAE)
}

\author{
Pepa Lozano Ramírez | directora del MAE \\ URL de la contribución <www.iaph.es/revistaph/index.php/revistaph/article/view/3728>
}

\section{RESUMEN}

Espera es un municipio de 4.000 habitantes, ubicado al norte de la provincia de Cádiz, con una gran riqueza a nivel arqueológico. Sus dos yacimientos principales son Carissa Aurelia, declarado BIC en 2003 (Decreto 339/2003, de 2 de diciembre), y Esperilla, identificada por algunos autores como la ciudad de Cappa; su secuencia poblacional empieza en el Neolítico y continúa prácticamente de manera ininterrumpida hasta época medieval. Completan su rico patrimonio arqueológico e histórico el castillo de Fatetar, la iglesia Santa María de Gracia (siglo XVI) y la antigua casa de la Cilla (siglo XVIII).

A pesar del notable interés de este patrimonio, hasta 1998 no comenzó su visión como motor para la revitalización de turismo en la localidad y su puesta en valor con este fin. En 2001 se inauguró la Exposición permanente mundo funerario íbero-romano, germen del futuro Museo Arqueológico de Espera (MAE), en la que se mostraban piezas arqueológicas tanto de los dos yacimientos principales como de los numerosos secundarios que abundan por todo el término municipal. Desde entonces permanece abierto al público convertido en un atractivo más de este pueblo que, aun contando con un gran patrimonio, es uno de los más desconocidos de toda la comarca de la Sierra de Cádiz por estar ubicado fuera de la órbita del circuito turístico más renombrado, la ruta de los Pueblos Blancos.

\section{Palabras clave}

Bornos (Cádiz) | Cádiz (Provincia) | Carissa Aurelia | Ciudades | Edad del hierro II |Época romana | Espera (Cádiz) | Esperilla | Museo Arqueológico de Espera (Cádiz) | Patrimonio arqueológico | Sierra de Cádiz | Yacimientos arqueológicos | 




Actividades con escolares en el MAE | foto Pepa Lozano Ramírez, de todas las imágenes si no se indica lo contrario 


\section{DE EXPOSICIÓN PERMANENTE MUNDO FUNERARIO ÍBERO-ROMANO EN ESPERA A MUSEO ARQUEOLÓGICO DE ESPERA (MAE)}

Los vecinos de Espera y las distintas corporaciones municipales siempre han mostrado una gran preocupación por conservar y recuperar el rico patrimonio arqueológico del que disponían. Los yacimientos de Carissa Aurelia y Esperilla han aportado abundante material arqueológico de calidad. Los descubrimientos son consecuencia unas veces, la mayoría, por desgracia, de actuaciones clandestinas, otras veces son resultado de las escasas intervenciones de urgencia que se han realizado, o de hallazgos casuales a raíz de tareas agrícolas o escorrentías.

La creación de un museo local en el que se expusieran esos hallazgos arqueológicos era una aspiración que venía de antiguo. Sin embargo, por motivos principalmente económicos, no fue una realidad hasta 2001, cuando, con motivo del inicio del proyecto Arqueosierra II promovido por la Mancomunidad de Municipios de la Sierra de Cádiz, cuyo fin era la puesta en valor del patrimonio arqueológico de la Sierra de Cádiz, el Ayuntamiento de Espera decidió destinar los fondos necesarios para la adecuación de la planta baja del edificio de la Casa de la Cultura como lugar de exposición de las piezas arqueológicas y la colección de escultura íbero-romana allí almacenada, además de materiales que estaban en manos de particulares, los cuales habían mostrado su disposición a cederlos una vez que se contara con un espacio adecuado. La Casa de la Cultura es una casa-palacio del siglo XVIII, de propiedad municipal, en cuya planta primera se ubicaba la biblioteca pública. La planta baja, por entonces desocupada, se acondicionó para la instalación de la exposición permanente. Se unieron varias estancias separadas por tabiques y se renovaron tanto el pavimento como la instalación eléctrica. A nivel museográfico, se diseñaron la cartelería y las vitrinas, y se decidió el recorrido de la exposición. Entretanto se procedió a la recogida, recuperación y catalogación del material arqueológico. Finalmente, en julio de 2001, se inauguró oficialmente la llamada Exposición mundo funerario íbero-romano en Espera, pues la mayor parte de los materiales expuestos, incluida la colección de escultura, estaban relacionados con el tema de la muerte.

En 2003, a instancias de la Delegación Provincial de Cultura de Cádiz, se redactó un Proyecto de homologación, con el fin de que la exposición pasara a formar parte del Registro Andaluz de Museos y Colecciones Museográficas.

La Dirección General de Instituciones del Patrimonio Histórico resolvió favorablemente quedando así anotado de forma preventiva en el Registro de Museos (RESOLUCIÓN, 2004). En el período que transcurre de 2003 a 2005 se dotó a la exposición de un laboratorio y se trasladó la biblioteca municipal, quedando libre la planta primera para una futura ampliación del museo. 

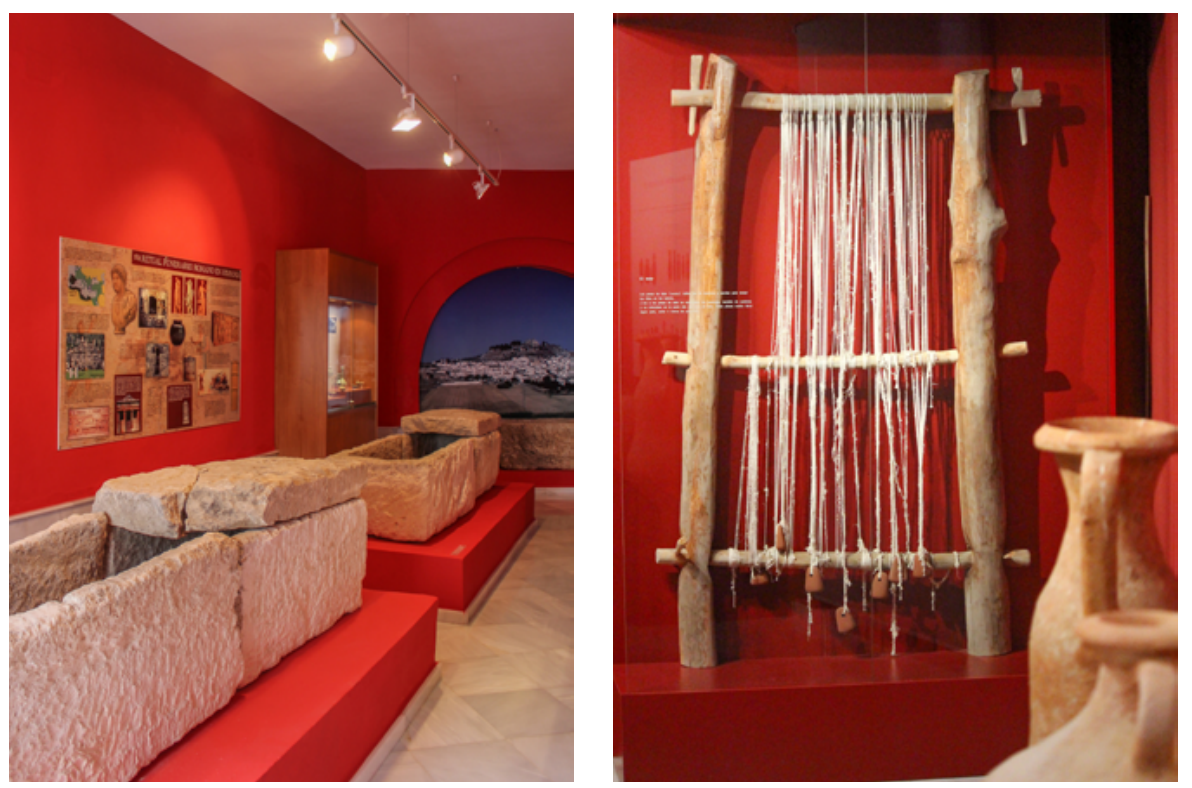

En 2006 la exposición cerró sus puertas para someterse a una importante reforma gracias al proyecto Cultur-Cad promovido por el Instituto de Empleo y Desarrollo Socioeconómico y Tecnológico de Diputación. El objetivo era adecuar el edificio entero para ser la sede definitiva del museo y la ampliación de la exposición a la planta primera. Al mismo tiempo que se ejecutaba la obra se redactó un proyecto museológico para proporcionar una estructura coherente al contenido del futuro espacio. Desde el punto de vista museográfico se diseñaron las vitrinas para las piezas, la señalética de todo el edificio y se creó el logotipo del que sería a partir de entonces denominado MAE, acrónimo de Museo Arqueológico de Espera, inaugurado el 29 de octubre de 2007.

La exposición quedó dividida temática y espacialmente ofreciendo un recorrido histórico a través de las piezas arqueológicas exhibidas.

\section{Planta baja: Prehistoria, protohistoria y mundo funerario romano. El mundo de los muertos}

En la planta baja se expone una representación de los utensilios empleados por el hombre de la sierra gaditana desde el Paleolítico-Neolítico hasta el bronce final: herramientas líticas talladas y pulimentadas, molinos de mano, utensilios de bronce, restos cerámicos, etc. El contenido más destacado de la sala es una amplia muestra de piezas pertenecientes al mundo funerario íbero-romano, entre las que destaca la importante colección de escultura zoomorfa, principalmente leones, y antropomorfa, hallada en la zona de la necrópolis de los yacimientos del término municipal de Espera. La sala está rodeada de paneles explicativos relacionados con la temática principal de la sala.

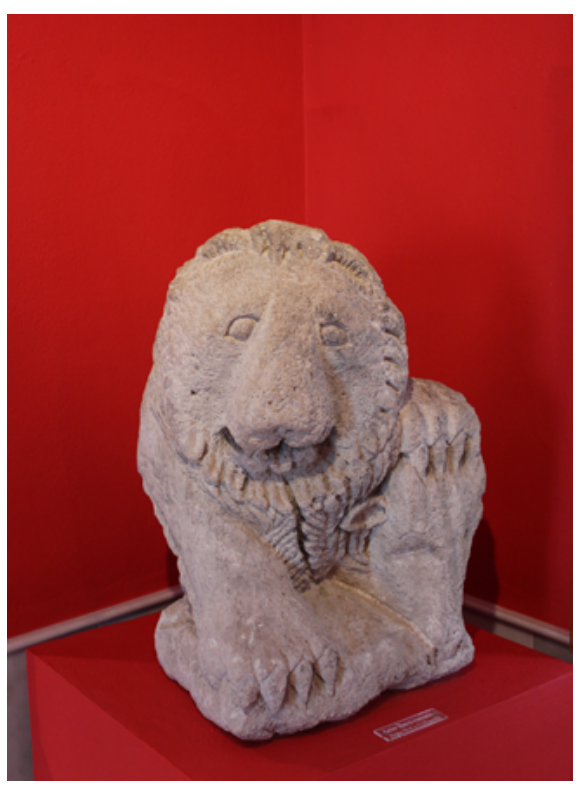

Vista general de la sala 2 de la planta baja Reproducción de telar. Planta primera León íbero-romano. Planta baja 


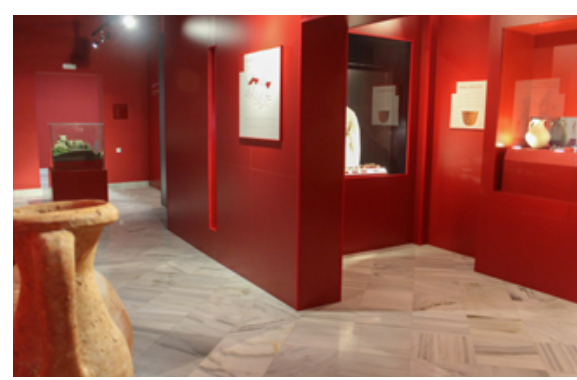

Vista general de la planta primera

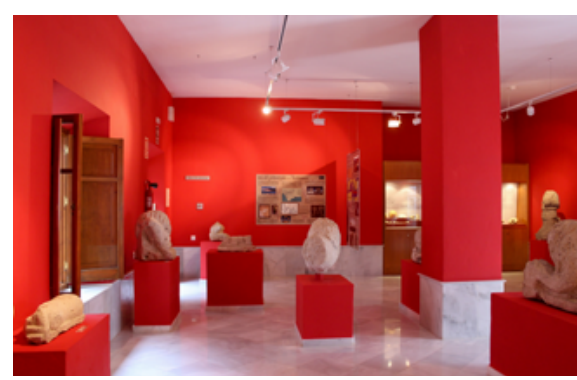

Vista general de la planta baja

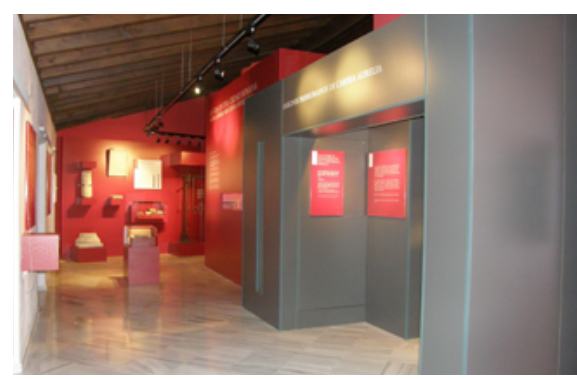

Vista general planta primera

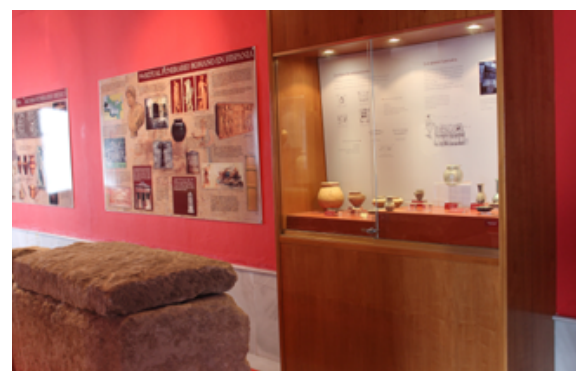

Sarcófagos tardorromanos y vitrina con ajuares funerarios. Planta baja

\section{Planta primera: La vida en la urbe y el castillo de Fatetar. El mundo de los vivos}

En contraposición al mundo funerario, en la planta primera el visitante descubrirá cómo era la vida en una ciudad romana. Tras una breve introducción sobre la etapa prerromana, la exposición nos traslada a la vida cotidiana en las urbes de Carissa Aurelia y Esperilla a través de la arquitectura, el comercio, la vestimenta de los habitantes de los yacimientos, etc. Se exponen piezas escultóricas, monedas ibéricas y romanas, elementos relacionados con la construcción (basas de columnas, fustes, tégulas, fragmentos de cornisas, de capiteles, plomadas...), pesas de telar, piedras de molino, reproducciones de ánforas, recipientes de cerámica y adornos personales como anillos, fíbulas, pinzas, espejos, etc. Continúa con la época medieval, con especial mención del castillo de Fatetar.

Se ha procurado que la exposición sea lo más didáctica posible, pues gran parte del público que acude al museo son escolares de toda la provincia. Se han redactado actividades para los distintos niveles educativos que se envían previamente a los grupos de alumnos para que acudan con una serie de conocimientos adquiridos y también se han preparado juegos que se realizan durante la visita, con el objetivo de que el aprendizaje sea ameno y divertido. Asimismo se les inculca la importancia que tiene el patrimonio arqueológico e histórico y la necesidad de cuidarlo y salvaguardarlo para las generaciones venideras.

Además de los espacios expositivos, el MAE cuenta con dependencias administrativas, laboratorio, biblioteca y una sala de audiovisuales, donde se da por finalizada la visita con la proyección de un documental sobre el patrimonio de Espera y la comarca de la Sierra de Cádiz. Este espacio es también utilizado como sala de conferencias o para la realización de diferentes actividades organizadas por el museo o por el ayuntamiento.

El próximo mes de julio se cumplirán 15 años de la inauguración de la exposición permanente. Durante todo este tiempo, a excepción de los meses en los que se realizó la segunda reforma, la exposición, luego Museo Arqueológico de Espera, ha estado abierto al público con horario fijo incluidos los fines de semana. EI MAE no solo ha cumplido con las funciones propias de un organismo de sus características: exponer, conservar, investigar y difundir el patrimonio, sino que se ha convertido en un espacio cultural de referencia en la localidad que excede las funciones propias de un museo. Es un lugar de encuentro vivo que ya forma parte de la identidad cultural de los vecinos de Espera.

EL MAE quedó definitivamente inscrito en el Registro de Museos de Andalucía por la Orden de 30 de enero de 2009 (ORDEN, 2009). 


\section{BIBLIOGRAFÍA}

- RESOlUCión de 12 de enero de 2004, de la Dirección General de Instituciones del Patrimonio Histórico, por la que se hace pública la relación de los museos anotados preventivamente en el año 2003 en el Registro de Museos de Andalucía. Boletín Oficial de la Junta de Andalucía, n. ${ }^{\circ}$ 36 , de 23 de febrero de 2004

- ORDEN de 30 de enero de 2009, por la que se autoriza la creación del Museo Arqueológico Municipal de Espera, en Espera (Cádiz), y se ordena su inscripción en el Registro de Museos de Andalucía. Boletín Oficial de la Junta de Andalucía, n. ${ }^{\circ}$ 51, de 16 de marzo de 2009

- LEY 8/2007 de 5 de octubre de Museos y Colecciones Museográficas de Andalucía. Boletín Oficial de la Junta de Andalucía, n. ${ }^{\circ} 205$, de 18 de octubre de 2007

- BARRAgÁN JANÉ, M. (2001) Sistema Andaluz de Museos y registro de Museos de Andalucía. PH: Boletín del instituto Andaluz del Patrimonio Histórico, n. ${ }^{\circ} 34$, marzo, 2001, pp. 159-165 